\title{
Trends in Enterprise Architecture Practice - a Survey
}

\author{
Ulrik Franke $^{1}$, Mathias Ekstedt ${ }^{1}$, Robert Lagerström ${ }^{1}$, \\ Jan Saat ${ }^{2}$, Robert Winter ${ }^{2}$ \\ 1 Industrial Information and Control Systems, Royal Institute of Technology, \\ Osquldas väg 10, 10044 Stockholm, Sweden \\ \{ulrikf, mek101, robertl\}@ics.kth.se \\ 2 Institute of Information Management, University of St Gallen, \\ Mueller-Friedberg-Strasse 8, 9000 St Gallen, Switzerland \\ \{jan.saat, robert.winter\}@unisg.ch
}

\begin{abstract}
In recent years, Enterprise Architecture (EA) has become a discipline for business and IT-system management. While much research focuses on theoretical contributions related to EA, very few studies use statistical tools to analyze empirical data.

This paper investigates the actual application of EA, by giving a broad overview of the usage of enterprise architecture in Swedish, German, Austrian and Swiss companies. 162 EA professionals answered a survey originally focusing on the relation between IT/business alignment (ITBA) and EA. The dataset provides answers to questions such as: For how many years have companies been using EA models, tools, processes and roles? How is ITBA in relation to EA perceived at companies? In particular, the survey has investigated quality attributes of EA, related to IT-systems, business and IT governance. One important result is some interesting correlations between how these qualities are prioritized. For example, a high concern for interoperability correlates with a high concern for maintainability.
\end{abstract}

Key words: Enterprise architecture, Survey, Practice, Trends

\section{Introduction}

Managing IT-systems today is a complex business [1]. In recent years, Enterprise Architecture (EA) has become a discipline for business and IT-system management [1]. EA describes the fundamental artifacts of business and IT as well as their interrelationships $[1,2,3,4,5]$. Architecture models constitute the core of the approach and serve the purpose of making the complexities of the real world understandable and manageable to stakeholders [3]. A main concept in EA is the metamodel, which acts as a pattern for the instantiation of the architectural models. In other words, a metamodel is a language representation used when creating models $[2,4,6,7]$. EA ideally aids the stakeholders of the enterprise to effectively plan, design, document, and communicate IT and business related issues, i.e. they provide decision support for the stakeholders [7]. 
In research EA is increasing in visibility and the strengths are frequently discussed. One question that has not been thoroughly addressed is the actual extent to which EA is employed in the industry and how this usage looks. Many research papers focus on theoretical contributions related to EA. Some use case studies to exemplify or test their EA contributions, but very few use statistical tools to test hypotheses related to EA. Thus, it is difficult to find any proof of EA really being applicable. This might be due to the fact that few companies actually employ EA today, or it may be a sign of the immaturity of the discipline. This paper does not provide this kind of proof either, however it does give some empirical input for discussion and other researchers might find interesting hypotheses to test in their work.

The contribution of this paper is twofold. Firstly, this paper aims at giving a broad overview of the usage of enterprise architecture in Swedish, German, Austrian and Swiss companies. $162 \mathrm{EA}$ professionals answered a survey originally focusing on the relation between IT/business alignment (ITBA) and EA. While the results have been employed elsewhere in efforts to create actionable artifacts to achieve high ITBA $[8,9]$, the dataset can also be used in a more descriptive fashion to answer questions such as: For how many years have companies been using EA models, tools, processes and roles? How is ITBA in relation to EA perceived at companies? How are IT-system, business and IT governance concerns perceived and prioritized at companies?

Secondly, the survey presented in this paper focused on IT/business alignment and its relation to different quality attributes of enterprise architecture, i.e. qualities of the business such as flexibility and efficiency, IT governance e.g. plan/organize and IT-systems for example availability and maintainability. By employing correlation analysis among these qualities we found that the companies prioritize these differently. Our main findings show that companies who prioritize performance also prioritize availability, that companies who prioritize interoperability also prioritize maintainability, that companies who prioritize usability also prioritize suitability, and that companies who prioritize decision support also prioritize control and follow up. Based on this correlation analysis future research focus can be concentrated on the most sought after aspects of EA. In the long run these aspects can influence the content of the EA metamodels used in different companies $[10,8]$.

\subsection{Outline}

The remainder of this paper is structured as follows. Section 2 contrasts the present contribution with some related work in the fields of Enterprise Architecture. In section 3, the survey areas of IT-system qualities, business qualities and IT governance qualities are detailed, followed by a description of the data collection method in section 4 . Section 5 is the locus of the main contribution, presenting the data collected through the survey along with an analysis. Section 6 contains a discussion of the results, and some concluding remarks are given in section 7 . 


\section{Related work}

To place the present contribution in a proper context, this section outlines some related work and important concepts. The main research discipline is covered, namely enterprise architecture.

EA has been proposed as an approach for managing the business and IT on a strategic level. EA targets a holistic and unified scope of an organization $[11,12]$. This overarching perspective is also present in the ISO/IEC 42010:2007 standard, defining architecture as "the fundamental organization of a system, embodied in its components, their relationships to each other and the environment, and the principles governing its design and evolution" [13]. As a consequence of this wide scope, EA is typically not limited to IT, but also encompasses the relation and support of IT to the business. Thus, in many respects EA can be seen as a tool for achieving alignment between business and IT.

If the joint scope of IT and business is one defining part of EA, its modelbased methodology is another. As the name hints, architectural descriptions are central in EA. These descriptions include entities covering a broad range of phenomena, such as strategic aspects, organizational structure, business processes, software and data, as well as IT infrastructure [2, 3, 14]. A large number of EA frameworks have been proposed by the community, each detailing the kind of entities that should be part of the modeling effort. Some examples are $[4,15,16,17]$.

Essentially, EA models serve the purpose of helping various stakeholders in an organization to document and thus understand the complex enterprise, analyze the properties of current and potential future scenarios, plan and design future scenarios and the road to get there, as well as communicating the current and future state of affairs to other stakeholders in the organization. Furthermore, by focusing on particular needs of decision-makers - modeling not for modeling's sake, but for particular purposes - EA can be used as a powerful decision-support tool [6].

Wai Fong Boh and Daniel Yellin [18] present a study focusing on the employment of enterprise architecture standards and their effect on information technology management. They ask two research questions: (i) how do different governance mechanisms affect the use of EA standards? (ii) to what extent does the use of EA standards help organizations improve the sharing and integration of IT resources across the enterprise? These research questions are addressed by testing eight hypotheses, for instance: Organizations that have mechanisms to facilitate stakeholder involvement are more likely to see greater use of and conformance to EA standards. The hypotheses were tested with data collected in a survey sent to 47 organizations. 112 responses were obtained from the survey. By using the partial least squares (PLS)-based structural equation modeling (SEM) they found that (i) each type of governance mechanism had a different impact on each type of EA standard, and (ii) the use of EA standards was significant in helping organizations to effectively manage all four types of IT resources. 
Sabine Buckl et al., in a survey of EA tools, investigate the expectations regarding EA amongst industrial practitioners [19]. However, the scope of this investigation differs from the scope of the present paper.

\section{Research framework}

In the subsequent subsections, each of the three areas - (i) IT-system qualities, (ii) business qualities, and (iii) IT governance qualities - is detailed.

\subsection{IT-System Qualities}

The IT-system qualities employed are based on the ISO 9126 standard [13, 20, $21,22,23]$. These qualities have also been used in the EA research at the Royal Institute of Technology (KTH), perhaps most prominently in the book "Enterprise Architecture - Models and analyses for information systems decision making" [6].

Performance, or efficiency, as the ISO/IEC 9126 labels it, is a quality that characterizes how much work a system can perform and how fast. Performance is defined as the degree to which an IT-system can meet its objective in terms of scalability and responsiveness [24].

Interoperability is described as the ability of two or more systems or components to exchange information and to use that information [25]. Interoperability is defined in terms of two kinds of data exchangeability, one related to data formats and the other related to a user's attempts to exchange data [13].

The availability of a system indicates how often a system is ready to deliver its services to its users. Post factum, availability is defined as the ratio between the system's time in service (uptime) and the total time (uptime plus downtime), $[6,26]$.

The most common definition of IT-system security is how well the system is capable of preserving the confidentiality, integrity and availability of its internal information [27, 28].

The usability of a system reflects how easy it is for a user to interact with and perform his or her tasks in the system. [21] defines usability as the understandability, learnability, operability and attractiveness of an IT-system.

The accuracy of an IT-system is measured by the degree to which it produces resulting data that is accurate and precise. This is determined by comparing the output value with the expected or "real" value [6].

The ease with which an IT-system can be modified or adapted to a changed environment is referred to as maintainability, sometimes also identified as modifiability [25]. Inspired by [29], maintainability is defined by five sub-qualities, viz. flexibility, reusability, extensibility, portability, and integrability. These describe the different kinds of changes a system can be exposed to during its lifetime.

The suitability of an IT-system is the degree to which the functionality of the system supports the system's intended work tasks. That is, a suitable system 
offers the functions specified in the requirements specification, and meets user expectations with regard to functionality. The definition of suitability used here is borrowed from [13]. This definition stipulates that a system's suitability is contingent upon the systems functional adequacy, functional implementation completeness, functional implementation coverage and functional specification stability.

\subsection{Business Qualities}

The business qualities are based on a taxonomy originally presented by [30], which is based on a literature consolidation of over 500 papers and 20 books. The particular subset of this taxonomy employed in the present survey is that used by [31].

Flexibility is defined as the degree to which the business processes and organizational units in a company have the ability to adapt to changes in market conditions/requirements, e.g. changed demand, political and economical factors.

Efficiency concerns the degree to which the business processes in a company exhibit short manufacturing times/lead times/cycle times/work times, much automation of work etc.

Effectiveness is the degree to which the business processes in a company produce what the market demands and spend little time on paperwork and administration.

Integration and coordination focuses on the degree to which the organizational units in a company have the ability to integrate and coordinate different parts of the organization, i.e. coordination of the production and the distribution department, of the sales and production planning departments etc.

Decision support deals with the degree to which an organizational unit has proper decision support, i.e. makes well-informed decisions, decisions are taken close to operations, decisions have high reliability and low uncertainty, decisions made are accepted by the organization etc.

Control and follow up is defined as the degree to which an organization have the ability to control and follow up work i.e. decisions are evaluated in retrospect, lessons learned are documented and re-used, new projects take previous experiences into account etc.

Organizational culture means to what degree the organizational culture in a company is appreciated by the people working at the company, i.e. there is a high job satisfaction and motivation, no negative stress, low numbers of sick leave etc.

\subsection{IT Governance Qualities}

The IT governance qualities are based on the four main processes of the wellknown COBIT standard [32].

Plan and organize covers strategy and tactics, and concerns the identification of the way IT can best contribute to the achievement of the business objectives. 
Acquire and implement is about realizing the IT strategy, identifying, developing, or acquiring IT solutions, as well as implementing and integrating these into the business processes.

Deliver and support is concerned with the actual delivery of required services, which includes service delivery, management of security and continuity, service support for users, and management of data and operational facilities.

Monitor and evaluate addresses performance management, monitoring of internal control, regulatory compliance and governance in order to keep or improve quality and compliance with control requirements.

Compared to the IT-system and business qualities, the IT governance qualities might prima facie look more like activities. However, this should be interpreted as an operationalization of IT governance qualities in terms of maturity of the IT processes. Thus, the IT processes per se are not our primary interest here.

\section{Data Collection}

An on-line survey was used for data collection. Prior to distribution, the survey was pretested to a select number of EA experts and valuable comments were received and addressed. Invitations were emailed to EA professionals in Sweden, Switzerland, Austria and Germany. The email addresses were condensed from the attendance lists of EA practitioner conferences that have been organized by the authoring institutions. Additionally a web link to the survey was posted on several EA community websites. Out of 1105 invitations sent, 92 emails bounced, 339 persons started and 174 persons completed the survey. The on-line survey was active for ten days (September 11-21, 2009). The survey included a final question regarding the respondent's confidence with his or her answers. Twelve persons stated weak confidence so their answers were not further considered. A total of 162 completely filled-out surveys are subjected to the analysis below. Figure 1 describes the dataset in detail.

The survey is comprised of four parts: Part one of the survey contains questions regarding the background of the respondents such as industry, country, and company size as well as the respondent's role and involvement with EA. Respondents employed by a consulting company had the option to answer on behalf of a client company. 43 respondents used this option. The second part of the survey has two sections. The first section contains questions addressing EA use for IT/business alignment and the importance and perceived maturity of IT/business alignment at the respondent's company. Section two contains more detailed questions related to IT/business alignment and the positioning of the IT department within the respondent's company. The third part of the survey addresses the qualities regarding IT, business, and IT governance as presented in section 3. For each quality one statement was posted and the respondents were asked to mark the actual (as-is) situation (degree of realization) and desired (to-be) situation (importance for future realization) on a five-point Likert scale (where 1 equals very low, 2 equals low, 3 equals medium, 4 equals high, 


\begin{tabular}{lrr} 
Industry & Count & Percent \\
\hline Financial industry & 49 & $30.2 \%$ \\
Utility & 23 & $14.2 \%$ \\
Manufacturing & 17 & $10.5 \%$ \\
Other & 13 & $8.0 \%$ \\
Transportation & 12 & $7.4 \%$ \\
Telecommunication & 10 & $6.2 \%$ \\
Software industry & 8 & $4.9 \%$ \\
Public sector & 7 & $4.3 \%$ \\
Defense/Military & 7 & $4.3 \%$ \\
IT/Management consulting & 4 & $2.5 \%$ \\
Health care/Pharmaceutical & 3 & $1.9 \%$ \\
Engineering/Architecture & 3 & $1.9 \%$ \\
Academia/Research & 2 & $1.2 \%$ \\
Tourism & 2 & $1.2 \%$ \\
Retail & 2 & $1.2 \%$ \\
\hline
\end{tabular}

\begin{tabular}{lrr} 
Size of company & Count & Percent \\
\hline$<100$ employees & 15 & $9.3 \%$ \\
$100-1.000$ & 32 & $19.8 \%$ \\
$1.001-5.000$ & 33 & $20.4 \%$ \\
$5.001-10.000$ & 15 & $9.3 \%$ \\
$10.001-25.000$ & 28 & $17.3 \%$ \\
$>25.000$ & 39 & $24.1 \%$ \\
\hline & 162 & $100.0 \%$
\end{tabular}

\begin{tabular}{lrr} 
Area of activity & Count & Percent \\
\hline Business management & 28 & $17.3 \%$ \\
Business unit & 22 & $13.6 \%$ \\
IT department & 52 & $32.1 \%$ \\
IT management & 60 & $37.0 \%$ \\
\hline & 162 & $100.0 \%$
\end{tabular}

\begin{tabular}{lrr} 
Country & Count & Percent \\
\hline Austria & 4 & $2.5 \%$ \\
Finland & 1 & $0.6 \%$ \\
Germany & 28 & $17.3 \%$ \\
Sweden & 73 & $45.1 \%$ \\
Switzerland & 56 & $34.6 \%$ \\
\hline & 162 & $100.0 \%$
\end{tabular}

Fig. 1. Data set description.

and 5 equals very high). For the to-be situation, the respondents were cautioned to keep in mind that resources are limited and that the most important concerns need to be prioritized. The final part of the survey contains a question on the respondents' confidence regarding the answers, as well as the possibility to submit questions and feedback to the authors.

\section{Analysis}

The section aims at presenting the analysis of the data collected in the survey and the results obtained from this analysis. The first subsection presents descriptive data from the survey, while the second subsection presents an exploratory correlation analysis among the questions.

\subsection{Enterprise Architecture - Descriptive Data}

In the following, descriptive data from the survey is presented in the form of box plots. As is common, these plots contain five basic characteristics of the data sets: The maxima and minima, the median, and the first and third quartiles cutting off the lowest and the highest $25 \%$ of the data sets respectively. In addition, the plots also display the arithmetic means of the data sets (marked by asterisks, $*)$.

Figure 2 displays experience of EA among the respondents. This is the only plot where outliers have been removed: one response on the tools question and two responses on each of the other questions claiming experience of more than 22 years have been removed. This cut-off limit was derived by setting the seminal 


\section{For how many years has your company been...}

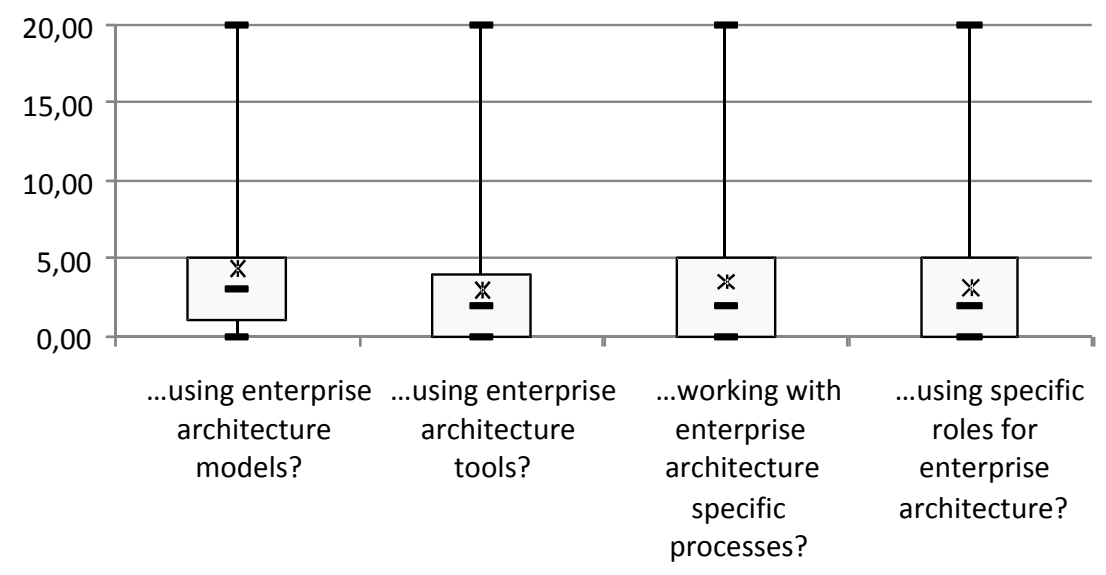

Fig. 2. Experience of EA among the respondents $(N=160, N=161, N=160$, $N=160)$.

Zachman 1987 publication [5] as a starting point for when it is meaningful to speak of EA and experience thereof.

As is evident from the plot, the adoption of models seems to precede the adoption of tools, processes and roles.

\section{Perception of IT/business alignment}

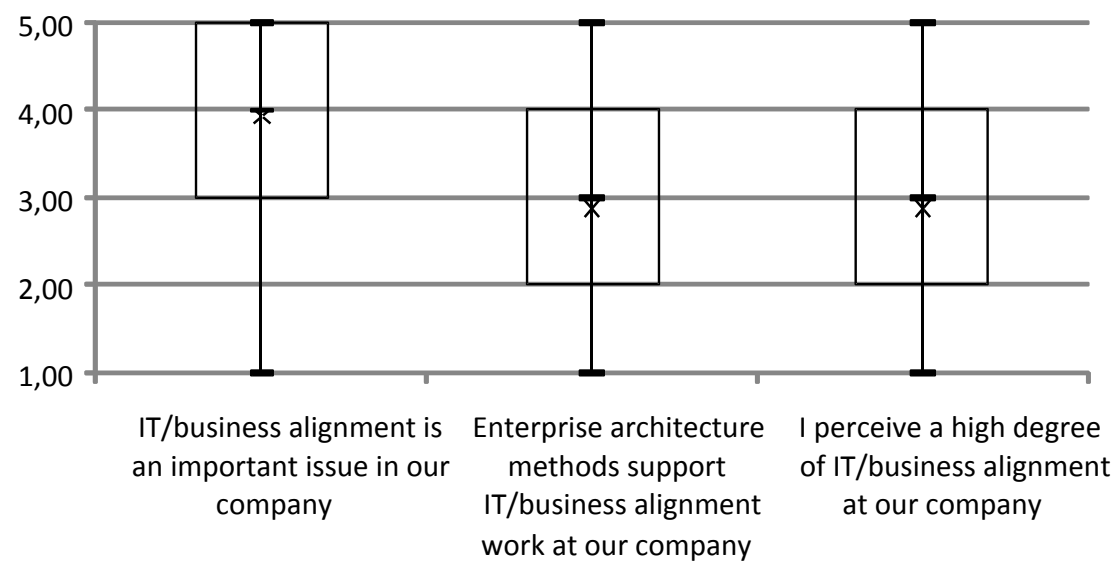

Fig. 3. The perception of IT/business alignment among the respondents $(N=153$, $N=159, N=160$ ). Scale from 1 (very low) to 5 (very high). 
Figure 3 illustrates the perception of IT/business alignment among the respondents. It is clear that the respondents perceive that this issue is important in their companies, but not that the actual level of alignment is equally high. EA methods are perceived to support IT/business alignment to a moderate extent.

\section{Software application/system concerns}

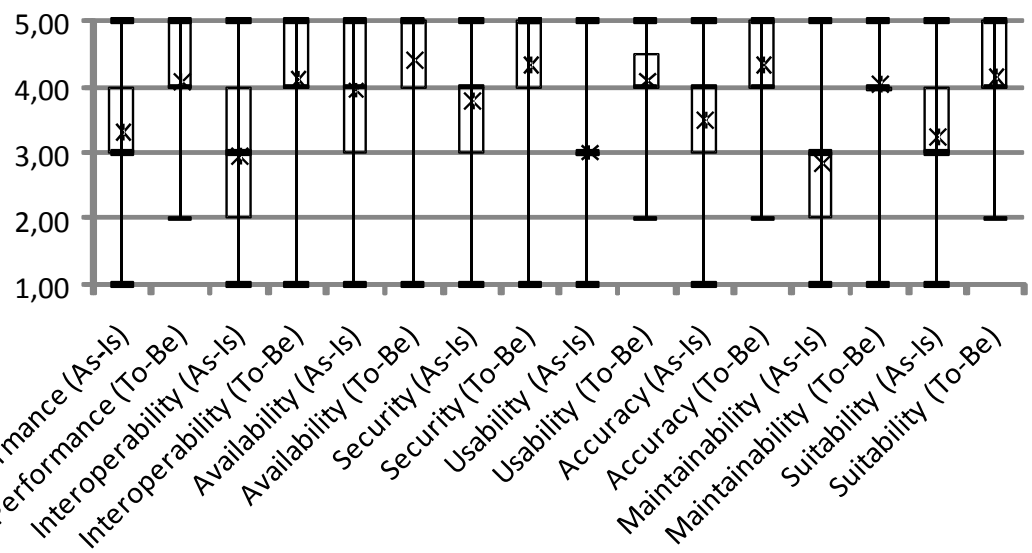

Fig. 4. The perception of actual and desired situations with regard to software application and system concerns $(N=158, N=158, N=157, N=158, N=159$, $N=158, N=154, N=157, N=160, N=159, N=159, N=156, N=158$, $N=155, N=160, N=160$ ). Scale from 1 (very low) to 5 (very high).

Figure 4 illustrates the perception of actual and desired situations with regard to software application and system concerns. One general trend that can be identified is that the future aspirations are higher than the present situation. The qualities are also valued slightly differently, with availability appearing as the most important concern and maintainability as the least important one.

Figure 5 illustrates the perception of actual and desired situations with regard to business concerns. Again, there is a trend of future aspirations that are higher than the present situation.

Figure 6 illustrates the perception of actual and desired situations with regard to IT governance concerns. Again, the trend of future aspirations being higher than the present situation is apparent.

\subsection{Qualities - Correlation and Descriptive Data}

Secondly, the survey data was used for a more exploratory analysis of the correlations found in the survey material. By looking through the entire material for strong correlations $(>0.5)$ significant on the 0.01 level, a few interesting observations could be made: 


\section{Business concerns}

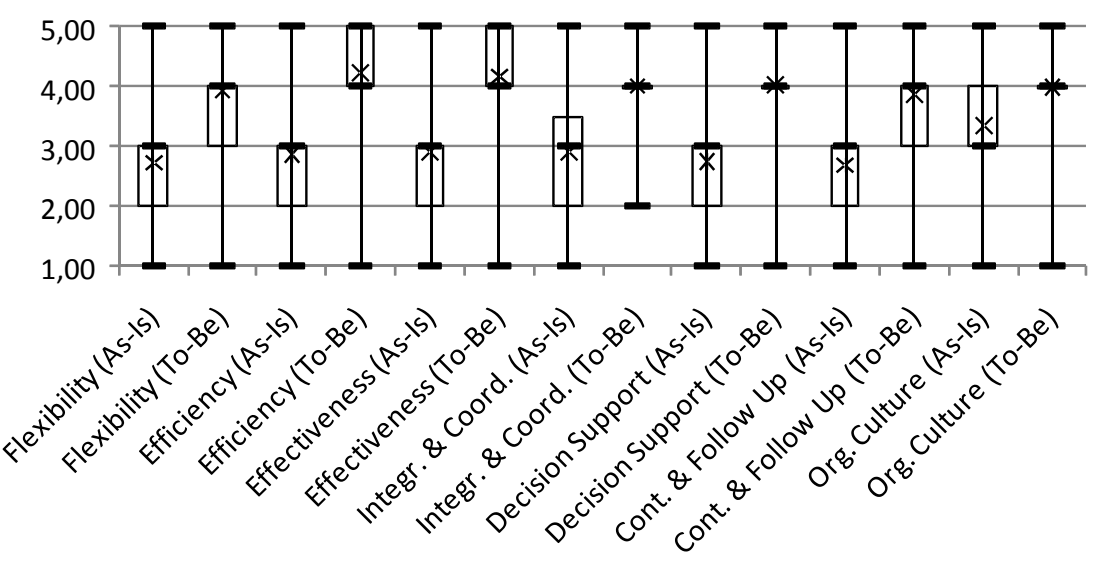

Fig. 5. The perception of actual and desired situations with regard to business concerns $(N=160, N=157, N=159, N=157, N=158, N=157, N=159, N=158$, $N=158, N=154, N=160, N=156, N=156, N=151$ ). Scale from 1 (very low) to 5 (very high).

\section{IT governance concerns}

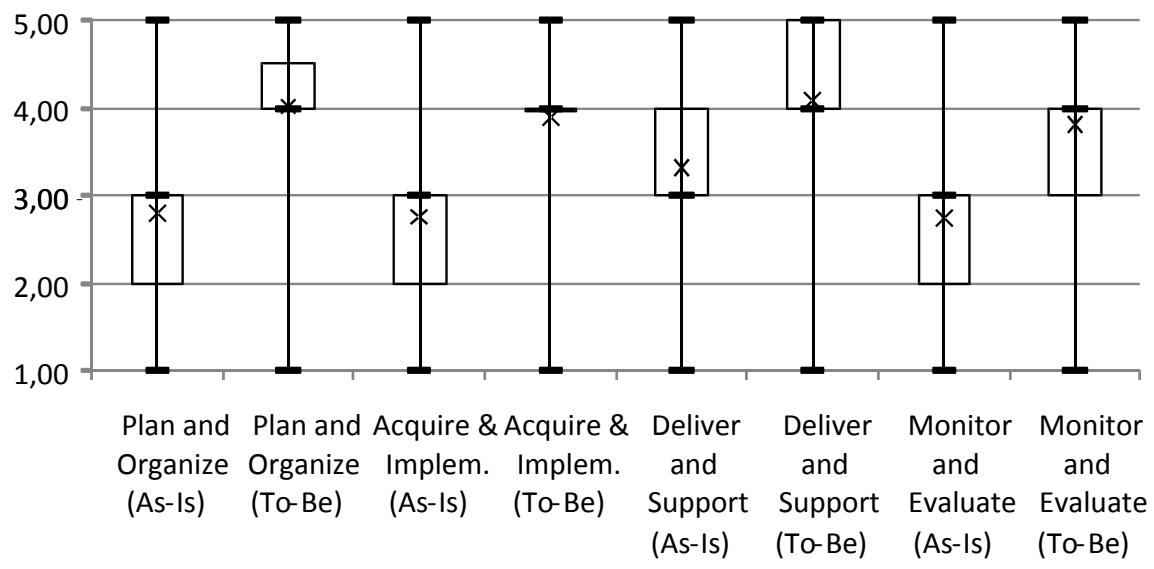

Fig. 6. The perception of actual and desired situations with regard to business concerns $(N=160, N=157, N=159, N=157, N=158, N=157, N=159, N=158$, $N=158, N=154, N=160, N=156, N=156, N=151$ ). Scale from 1 (very low) to 5 (very high).

The IT-systems quality attributes of Performance and Availability correlate strongly, both in the as-is situation (0.539) and the to-be situation (0.578), sig- 
nificant on the 0.01 level. This means that in companies where performance is an important concern, so is availability - and vice versa, that in companies where performance is not an important concern, neither is availability. This is a reasonable result, as these two qualities are rather similar. An IT-system that runs extremely slowly, i.e. shows poor performance, at some point simply should be considered completely unavailable.

The IT-systems quality attributes of Interoperability and Maintainability correlate strongly, both in the as-is situation (0.526) and the to-be situation (0.512), significant on the 0.01 level. This means that in companies where interoperability is an important concern, so is maintainability - and vice versa, that in companies where interoperability is not an important concern, neither is maintainability. This is a reasonable result, as these two qualities often relate to each other. One important reason why IT-systems need to be maintained and modified throughout their life-cycle is to perform integrations with other systems, i.e. for interoperability purposes. Conversely, systems can be interoperable by virtue of being easy to maintain, viz. the changes needed to become interoperable can easily be brought about.

The IT-systems quality attributes of Usability and Suitability correlate strongly, both in the as-is situation (0.517) and the to-be situation (0.538), significant on the 0.01 level. This means that in companies where usability is an important concern, so is suitability - and vice versa, that in companies where usability is not an important concern, neither is suitability. This is a reasonable result, as it should be expected that an IT-system suitable for its task is more user-friendly than a less suitable one.

Turning to the business qualities, Decision support and Control and follow up correlate strongly, both in the as-is situation (0.565) and the to-be situation (0.538), significant on the 0.01 level. This means that in companies where decision support is an important concern, so is control and follow up - and vice versa, that in companies where decision support is not an important concern, neither is control and follow up. This is a reasonable result, since concern for good decision-making should make follow up of the decisions a priority as well.

In the area of business qualities, correlations between Efficiency and Effectiveness were also found. However, we are reluctant to make too much of these findings, as there is a considerable risk of semantic confusion being responsible for these correlations.

It should be noted that, apart from being significant on the 0.01 level, all the correlations described above hold for both the as-is situation and the to-be situation. In the authors' opinion, this makes them strong candidates for future investigations. Still, it should be emphasized that these correlations have been found by an explorative investigation, not by prior hypothesis. The results of this section are summarized in Table 1. 
Table 1. Strong correlations ( $>0.5$ ) significant on the 0.01 level, between concerns for different qualities.

\begin{tabular}{llll} 
Quality 1 & Quality 2 & As-is correlation & To-be correlation \\
\hline Performance & Availability & 0.539 & 0.578 \\
Interoperability & Maintainability & 0.526 & 0.512 \\
Usability & Suitability & 0.517 & 0.538 \\
Decision support & Control and follow up & 0.565 & 0.538
\end{tabular}

\section{Discussion}

Considering the results presented in section 5, it is striking how some simple patterns re-appear throughout the survey results:

1. The differences between as-is qualities within each of the IT-system, business and IT governance categories are not very large. It seems that the bulk of companies judge themselves to be somewhere in the middle with regard to most IT-system, business and IT governance qualities.

2. The differences between to-be qualities are similarly small. This is more interesting, since the survey explicitly asked for prioritizations when it comes to the to-be situation. With limited resources, all qualities cannot be prioritized. The fact that the to-be responses, over the board, looks like just slightly elevated versions of the as-is responses is disconcerting. Three explanations are possible:

(i) The respondents themselves have tried to prioritize, but failed.

(ii) The respondents have truthfully reported the situation at their companies, and it is the companies that have failed to prioritize.

(iii) The answers are due to the structure and formulation of the survey. Explanation (iii) is certainly the case to some extent. For example, the on-line survey could have been programmed to force rankings from the respondents, rather than merely asking for them. Nevertheless, explanations (i) and (ii) are probably also present, indicating a lack of ability or willingness to prioritize on the part of either (i) individual respondents or (ii) their companies.

The explorative search for strong correlations reveals a few interesting pairs of concerns, as summarized in Table 1. A potential implication is that research dealing with these qualities could be made more useful by also taking the correlated quality into account. Thus, interoperability research such as [33] could be deemed more relevant by practitioners if also taking maintainability research such as [34], and vice versa.

\section{Conclusions}

There is a disconcerting trend to be found in the survey responses, viz. the inability to prioritize. While this trend ought to be further investigated - using 
methods that eliminate the risk of spurious answers - some preliminary conclusions can be drawn.

An implication for the communities of research, consultancy, tool vending etc. is the need to help companies prioritize properly. Note that this implication holds even if this survey trend is a spurious result of the way the questions were asked - if so, this shows how vulnerable the ability to prioritize is to haphazard circumstances.

If Enterprise Architecture is to become successful, it must not fall victim to company inability to prioritize, followed by thin-spread resources, and resulting disappointments. Interesting future work thus naturally includes research into the impact of prioritization - to what extent does the success of Enterprise Architecture depend on proper prioritization? Another area of future work is further investigation of the strong correlations found between concerns for various IT-system, business and IT governance qualities.

One additional implication for the research community is due to the pairs of concerns, as summarized in Table 1. This pairing can be used to make research on one concern more relevant by also including aspects of the other concern.

\section{References}

1. Ross, J.W., Weill, P., Robertson, D.: Enterprise Architecture As Strategy: Creating a Foundation for Business Execution. Harvard Business School Press (August 2006)

2. Lankhorst, M.: Enterprise Architecture At Work. Springer, Heidelberg (2005)

3. Winter, R., Fischer, R.: Essential layers, artifacts, and dependencies of enterprise architecture. Journal of Enterprise Architecture Volume 3, Number 2 (2007) $7-18$

4. The Open Group: The Open Group Architecture Framework (TOGAF) - version 9. The Open Group (2009)

5. Zachman, J.A.: A framework for information systems architecture. IBM Syst. J. 26(3) (1987) 276-292

6. Johnson, P., Ekstedt, M.: Enterprise Architecture - Models and Analyses for Information Systems Decision Making. Studentlitteratur (2007)

7. Kurpjuweit, S., Winter, R.: Viewpoint-based meta model engineering. Enterprise Modelling and Information Systems Architectures (EMISA) (2007)

8. Saat, J., Franke, U., Lagerström, R., Ekstedt, M.: Enterprise architecture meta models for IT/business alignment situations. In: Proc. 14th IEEE International EDOC Conference (EDOC 2010). (October 2010) To appear.

9. Saat, J., Winter, R., Franke, U., Lagerström, R., Ekstedt, M.: Analysis of it/business alignment situations as a precondition for the design and engineering of situated it/business alignment solutions. In: Proc. Hawaii International Conference on System Sciences (HICSS-44). (January 2011) To appear.

10. Lagerström, R., Saat, J., Franke, U., Aier, S., Ekstedt, M.: Enterprise meta modeling methods - combining a stakeholder-oriented and a causality-based approach. In: Enterprise, Business-Process and Information Systems Modeling, Lecture Notes in Business Information Processing. Volume 29., Springer Berlin Heidelberg (June 2009) 381-393 ISSN 1865-1348. 
11. Rohloff, M.: Framework and Reference for Architecture Design. In: Proceedings of the 14th Americas Conference on Information Systems (AMCIS 2008), Toronto. (2008) 1-14

12. Tyler, D., Cathcart, T.: A structured method for developing agile enterprise architectures. In: Proceedings of the International Conference on Agile Manufacturing (ICAM 2006), Norfolk, Virginia, USA. (2006) 1-8

13. International Standardization Organization/International Electrotechnical Committee: ISO/IEC 42010:2007 - Systems and software engineering - Recommended practice for architectural description of software-intensive systems. Technical report, ISO (2007)

14. Jonkers, H., Lankhorst, M., ter Doest, H., Arbab, F., Bosma, H., Wieringa, R.: Enterprise architecture: Management tool and blueprint for the organisation. Information Systems Frontiers 8(2) (2006) 63-66

15. Department of Defense Architecture Framework Working Group: DoD Architecture Framework, version 1.5. Technical report, Department of Defense, USA (2007)

16. Lankhorst, M., Proper, H., Jonkers, H.: The Architecture of the ArchiMate Language. Enterprise, Business-Process and Information Systems Modeling 367-380

17. Ministry of Defence: MOD Architecture Framework version 1.2.003. Technical report, Ministry of Defence, UK (September 2008)

18. Boh, W., Yellin, D.: Using enterprise architecture standards in managing information technology. Journal of Management Information Systems 23(3) (2007) 163-207

19. Buckl, S., Dierl, T., Matthes, F., Ramacher, R., Schweda, C.: Current and future tool support for ea management. In: Proceedings of Workshop MDD, SOA und IT-Management (MSI 2008), Oldenburg, Gito. (2008)

20. International Organization for Standardization: Software engineering-product quality-part 2: External metrics. International standard ISO/IEC TR 91262:2003(E), International Organization for Standardization (July 2003)

21. International Organization for Standardization: Software engineering-product quality-part 1: Quality model. International standard ISO/IEC TR 91261:2001(E), International Organization for Standardization (June 2001)

22. International Organization for Standardization: Software engineering-product quality-part 3: Internal metrics. International standard ISO/IEC TR 91263:2003(E), International Organization for Standardization (July 2003)

23. International Organization for Standardization: Software engineering-product quality-part 4: Quality in use metrics. International standard ISO/IEC TR 91264:2004(E), International Organization for Standardization (April 2004)

24. Smith, C., Williams, L.: Performance Solutions: a practical guide to creating responsive, scalable software. Addison-Wesley Boston, MA; (2002)

25. IEEE Standards Board: IEEE Standard Glossary of Software Engineering Technology. Technical report, The Institute of Electrical and Electronics Engineers (September 1990)

26. Franke, U., Johnson, P., König, J., Marcks von Würtemberg, L.: Availability of enterprise IT systems - an expert-based Bayesian model. In: Proc. Fourth International Workshop on Software Quality and Maintainability (WSQM 2010), Madrid. (March 2010)

27. Ferraiolo, D., Kuhn, D., Chandramouli, R.: Role-based access control. Artech House Publishers (2003)

28. Dhillon, G., Backhouse, J.: Technical opinion: Information system security management in the new millennium. Communications of the ACM 43(7) (2000) 128 
29. Matinlassi, M., Niemel, E.: The impact of maintainability on component-based software systems. In: Proceedings of the 29th IEEE EUROMICRO Conference "New Waves in System Architecture". (2003)

30. Gammelgård, M., Ekstedt, M., Gustafsson, P.: A categorization of benefits from IS/IT investments. In: Eurpoean Conference on Information Technology Evaluation. (September 2006)

31. Gustafsson, P., Franke, U., Höök, D., Johnson, P.: Quantifying IT impacts on organizational structure and business value with extended influence diagrams. In: Springer Lecture Notes in Business Information Processing. Volume Volume 15. (November 2008) 138-152

32. The IT Governance Institute: Control Objectives for Information and Related Technology (COBIT) 4.1. Technical report, The IT Governance Institute (2007)

33. Ullberg, J., Lagerström, R., Ekstedt, M.: A framework for interoperability analysis on the semantic web using architecure models. In: proceedings of Workshop on Enterprise Interoperability (IWEI 2008). (September 2008)

34. Lagerström, R., Johnson, P., Höök, D.: Architecture analysis of enterprise systems modifiability - models, analysis and validation. In: the Journal of Systems and Software (to appear). Volume 83. (2010) 1387-1403 